\title{
Inhibitory Effects of Prunella vulgaris L. Extract on 11 $\beta$-HSD1 in Human Skin Cells
}

\author{
Kyung-Baeg Roh $\mathbb{D}$, Deokhoon Park, and Eunsun Jung $\mathbb{C}$ \\ Biospectrum Life Science Institute, Yongin 16827, Republic of Korea \\ Correspondence should be addressed to Eunsun Jung; bioso@biospectrum.com
}

Received 7 February 2018; Revised 5 June 2018; Accepted 3 September 2018; Published 4 October 2018

Academic Editor: Yoshiyuki Kimura

Copyright (C) 2018 Kyung-Baeg Roh et al. This is an open access article distributed under the Creative Commons Attribution License, which permits unrestricted use, distribution, and reproduction in any medium, provided the original work is properly cited.

Glucocorticoids are a risk factor for age-induced skin structure and function defects, and the glucocorticoid-activating enzyme, $11 \beta$-hydroxysteroid dehydrogenase 1 (11 $\beta$-HSD1), represents a promising therapeutic target. Prunella vulgaris L. (PV) is a perennial and an edible herbaceous plant normally cultivated in Asia and Europe. A recent study demonstrated a broad range of biological activities of PV including immune modulatory, antiviral, antiallergic, anti-inflammatory, antioxidant, and antidiabetic. However, little is known about the inhibitory effect of PV on 11 $\beta$-HSD1. In this study, we investigated the inhibitory effect of Prunella vulgaris L. extract (PVE) and the underlying mechanism of $11 \beta$-HSD11 inhibition. Consistent with these results, cortisol levels were also reduced by PVE in vitro. The cortisone-induced translocation of glucocorticoids receptor (GR) was also attenuated. In addition, PVE inhibited a cortisone-mediated decrease in collagen content in skin. Collectively, these results suggest the beneficial effects of PVE in maintaining skin integrity.

\section{Introduction}

Glucocorticoid (GC) hormones are released in response to various physiological stressors and psychological stress [1]. It regulates various biological processes which induce diverse responses including differentiation, proliferation, and apoptosis [2]. The major GC, hydrocortisone, or cortisol is mainly synthesized and secreted in the adrenal cortex and regulated by adrenocorticotropic hormone (ACTH) under the control of hypothalamic-pituitary-adrenal (HPA) axis [3]. Various stressors, such as inflammation, viral infection, or feeling of strain and pressure, can stimulate the HPA axis [4]. Extra-adrenal production of cortisol has recently reported in various tissues [5]. Skin cells have also been reported to synthesize cortisol through activation of the enzyme, $11 \beta$ HSD1 $[6,7]$.

In skin, excessive GC production leads to marked skin integrity, including thinning and the dermal-epidermal junction (DEJ) flattening, decreased dermal cellularity, reduced collagen content, and dermal fibroblast proliferation [8-11]. Cortisol levels are regulated by isoenzymes of $11 \beta$-hydroxysteroid dehydrogenase 1 (11 $\beta$-HSD1), which catalyzes the intracellular conversion of inactive cortisone into active cortisol [12].

Blockade of $11 \beta$-HSD1 resulted in a significant improvement in age-induced skin structure and function defects, accompanied by accelerated wound healing $[7,13]$. These studies suggest that inhibition or downregulation of $11 \beta$ HSD1 provides beneficial effects for maintaining skin integrity.

Prunella vulgaris $\mathrm{L} .(\mathrm{PV})$ is a perennial and an edible herbaceous plant normally cultivated in Asia and Europe. PV has been used as a folk remedy for alleviating sore throats, reducing fever, and promoting wound healing [14]. In Asian countries, it has been used as a food or tea for a long time. A recent study showed that PV has a broad range of biological activities including immune modulatory, antiviral, antiallergic, anti-inflammatory, antioxidant, and anticancer [15-20]. PV has also been reported to be useful in the treatment of diabetes [21,22]. However, little is known about the inhibitory effect of PV on $11 \beta$-HSD1. In this study, we investigated the inhibitory effect of PV on $11 \beta$-HSD11 and its underlying mechanism. 


\section{Materials and Methods}

2.1. Preparation of Prunella vulgaris L. Extract. Prunella vulgaris L. (PV) was harvested in Jeju Island, Korea, from June to July and authenticated by Dr. Yong-Hwan Jung, Jeju Biodiversity Research Institute, Jeju Techno Park, Korea, where a voucher specimen (Voucher No. JBRI 150924-01). The aerial part of the plant was dried and grounded to a fine powder. Water extract of PV $(10 \% \mathrm{w} / \mathrm{v})$ was prepared by overnight extraction in sterile water at $40 \sim 50^{\circ} \mathrm{C}$ under the condition of slow shaking. The extracts were filtered through filter paper and then frozen on a freezing tray for $48 \mathrm{~h}$. A perfectly dried extract of PV was obtained after freeze drying of the liquid extract for $60 \mathrm{~h}$. The obtained extract was dissolved in distilled water for further experiments [23].

2.2. Cell Culture and Reagents. Human keratinocytes, HaCaT and normal human fibroblasts, and NHFs were maintained in DMEM (HyClone, Logan, UT, USA), containing 10\% FBS and $1 \%$ penicillin/streptomycin at $37^{\circ} \mathrm{C}$, under $5 \% \mathrm{CO}_{2}$. Human epidermal keratinocytes (HEKn) were maintained in EpiLife (Invitrogen, Carlsbad, CA, USA), containing Human Keratinocyte Growth Supplement (HKGS, Invitrogen, USA) at $37^{\circ} \mathrm{C}$, under $5 \% \mathrm{CO}_{2}$. Cortisone and BVT.2733 were obtained from Sigma Aldrich (St. Louis, MO, USA). $11 \beta$-HSD1 promoter reporter clone was purchased from GeneCopeia (Rockville, MD, USA). Anti-GR/NR3C1-PE was purchased from Novus Biologicals (Littleton, CO, USA).

2.3. High-Performance Liquid Chromatography. The aqueous extract of PV was quantitatively analyzed by HPLC. The HPLC system (Shimadzu, Kyoto, Japan) with a CBM-20A controller, LC-20AD pump, SPD-M20A PDA detector, and a SIL-20A autosampler was used for the analysis of PV. Data collection was performed using Shimadzu Lab Solution. All chromatographic separations were performed on a CAPCELL PAK C 18 UG120 column $(250 \mathrm{~mm} \times 4.6 \mathrm{~mm}, 5$ $\mu \mathrm{m}$, Shiseido, Tokyo, Japan) with $0.1 \%$ acetic acid/acetonitrile gradient system at ambient temperature with detection at 254 $\mathrm{nm}$. The amount of rosmarinic acid and caffeic acid in the water extract of PV were determined.

2.4. Cell Viability Assay. Cell viability was measured using the MTT (3-[4,5-dimethylthiazol-2-yl]-2,5-diphenyltetrazolium bromide, USB Corp., Cleveland, OH, USA) assay. Cells were plated in triplicate wells of 24-well plates and incubated overnight. Subsequently, the cells were treated with PVE for $24 \mathrm{~h}$, under a serum-free condition. Next, MTT reagent $(1 \mathrm{mg} / \mathrm{ml})$ was added to each well and the cells were incubated for $3 \mathrm{~h}$. The medium was then discarded and the cells solubilized with DMSO. The absorbance was measured at a wavelength of $570 \mathrm{~nm}$ using a spectrophotometer [24].

2.5. Transient Transfection and Luciferase Assay. The HaCaT cells were transfected with the $11 \beta$-HSD1 luciferase reporters (GeneCopoeia, Rockville, MD, USA) using SuperFect ${ }^{\circledR}$ Transfection Reagent (Qiagen, Hilden, Germany). After $24 \mathrm{~h}$ of incubation, the cells were incubated with PVE induced by cortisone for $24 \mathrm{~h}$. Subsequently, the cells were harvested and lysed, and the supernatants were measured for their luciferase activity using a BioLux ${ }^{\circledR}$ Gaussia Luciferase Assay Kit (New England Biolabs, Ipswich, MA, USA), and an Infinite ${ }^{\circledR} 200$ PRO luminometer (Tecan, AG, Männedorf, Switzerland).

2.6. Enzyme-Linked Immunosorbent Assay (ELISA). Cortisol concentration was quantified in culture supernatants of HaCaT after treatment with PVE using a commercially available ELISA kit (Enzo Biochem, New York, NY, USA). Cell culture supernatants were gathered $24 \mathrm{~h}$ after treatment with PVE and assayed for cortisol. Procollagen type I was quantified in the culture medium of cocultured NHFs using a commercially available ELISA kit (Takara Bio Inc., Japan). The standard curve was linearized and regression analysis was performed. The cortisol concentration was determined using a standard curve.

2.7. Immunocytochemistry. Glucocorticoid receptor (GR) translocation was determined by immunocytochemistry. Typically, $2 \times 10^{2}$ cells were plated in 96-well plates, cultured for $24 \mathrm{~h}$, and treated with cortisone in the presence or absence of GAE for $40 \mathrm{~min}$. The cells were fixed in $4 \%$ formaldehyde, permeabilized with $0.1 \%$ triton $\mathrm{X}-100$, and incubated with a PE-conjugated antihuman GR (Novus Biologicals, USA) for $2 \mathrm{~h}$. Subsequently, the cells were examined, using the IN Cell Analyzer 100 (GE Healthcare Lifesciences, Uppsala, Sweden).

2.8. Total RNA Extraction, cDNA Synthesis, and Quantitative $P C R$. Total RNA extraction was performed using RNeasy kit (Qiagen, Hilden, Germany); cDNA was synthesized using a PrimeScript 1st Strand cDNA synthesis kit (Takara Bio Inc., Japan), according to the manufacturer's instructions. The HSD11 $\beta 1$, COL1A1, and NR3C1 mRNA were measured by real-time quantitative PCR. The primer sequences were as follows: HSD $11 \beta 1$ : forward $5^{\prime}$-CCAGAGATGCTCCAAGGAAAG-3', reverse $5^{\prime}$-TGGTGCCAGCAATGTAGTGT3'; NR3C1: forward 5'-TGTGCTGGAAGGAATGATTG3', reverse $5^{\prime}$-AGGGGTGAGTTGTGGTAACG-3'; COL1A1: forward $5^{\prime}$-GGACACAGAGGTTTCAGTGGT-3', reverse $5^{\prime}$-CACCATCATTTCCACGAGCA-3 ${ }^{\prime}$; GAPDH: forward $5^{\prime}$ TGCACCACCAACTGCTTAGC-3', reverse $5^{\prime}$-GGCATGGACTGTGGTCATGAG-3' . All mRNA data were normalized to GAPDH expression.

\subsection{In Vitro Coculture of Human Epidermal Keratinocytes} and Fibroblasts. We used the Millicell ${ }^{\circledR}$ Cell Culture insert (Millipore, Billerica, MA, USA), according to the manufacturer's instructions. Briefly, human epidermal keratinocytes and human fibroblasts were cocultured in transwell system. For HEKn, $1 \times 10^{3}$ cells were seeded in the upper chamber, with $8 \mu \mathrm{m}$-pore filters and lower chambers were seeded with fibroblasts at $5 \times 10^{4}$ cells for $24 \mathrm{~h}$. PVE, $11 \beta$-HSD inhibitor, and cortisone were added to the upper wells. After $72 \mathrm{~h}$ of incubation, cell culture medium and NHFs were harvested, and ELISA and real-time qPCR were performed to measure the levels of collagen. 


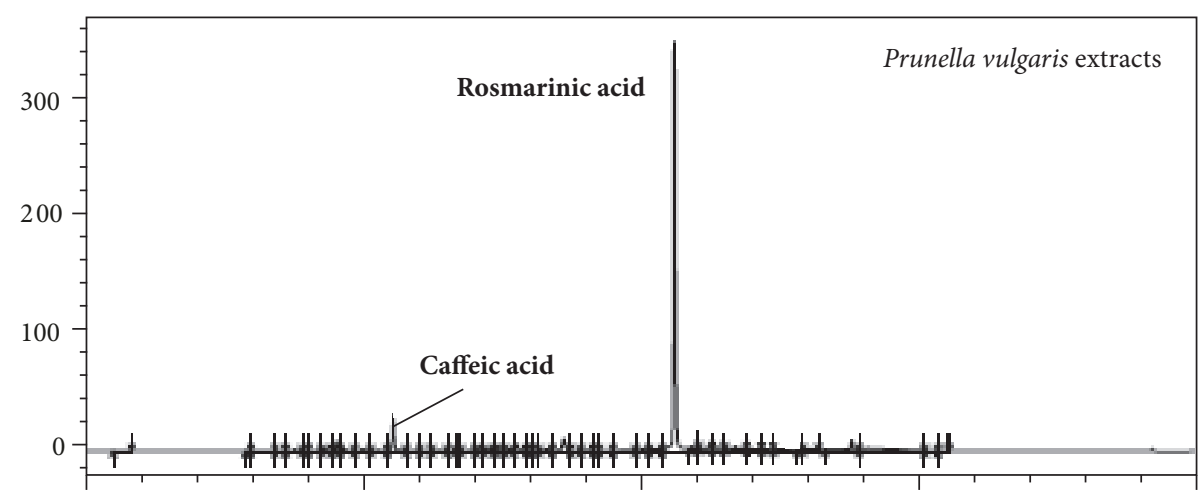

(a)

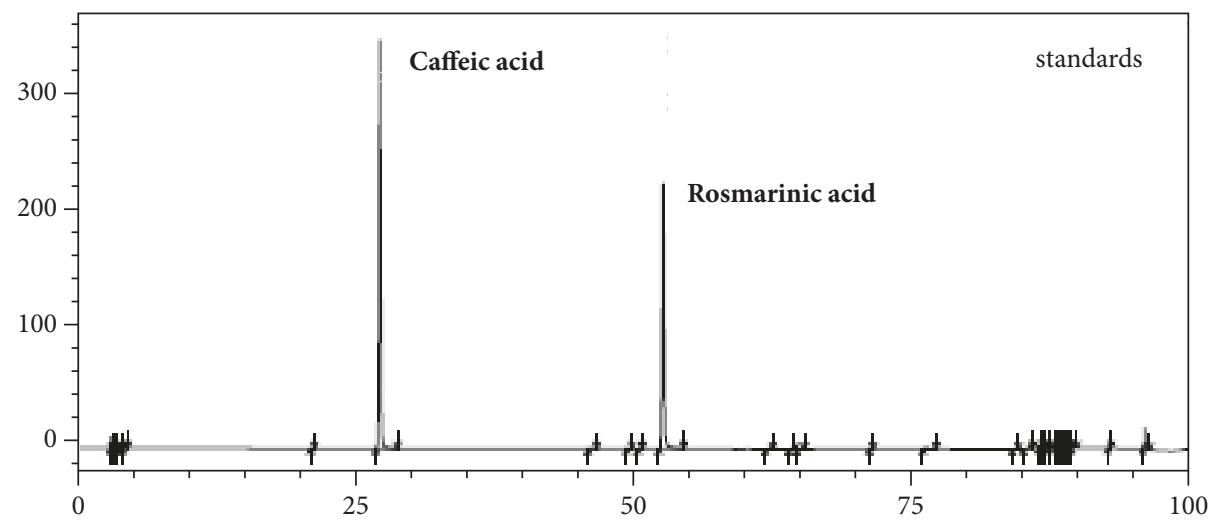

(b)

\begin{tabular}{lcc}
\hline Constituents & \multicolumn{3}{c}{$\begin{array}{c}\text { Prunella vulgaris extracts } \\
\mathrm{mg} / \mathrm{g}\end{array}$} & $\%$ \\
\hline Caffeic acid & 3.162 & 0.316 \\
Rosmarinic acid & 35.692 & 3.569 \\
\hline
\end{tabular}

(c)

FIGURE 1: Phytochemical analysis of PVE (a, b). Composition of Prunella vulgaris extract (PVE). (c) Quantitative analysis of the phytochemical activity of PVE.

2.10. Statistical Analysis. Differences between the control and treatment group were analyzed by Student's t-test. A $P<0.05$ was considered statistically significant.

\section{Results and Discussion}

3.1. Chemical Composition Analysis of PVE. The PVE contained $0.3 \%$ caffeic acid and $3.5 \%$ rosmarinic acid. Chromatograms of typical extracts and the mixed standards are shown in Figures 1(a) and 1(b). The results of the quantitative analysis are summarized in Figure 1(c).

3.2. PVE Inhibits 11 $\beta$-HSD1 Expression. To determine the inhibitory effects of PVE on $11 \beta$-HSD1, we investigated the effect of PVE on cortisone-induced $11 \beta$-HSD1 expression. A luciferase assay and real-time qPCR were performed to measure $11 \beta$-HSD1 expression. As shown in Figure 1(a), cortisone-induced activation of $11 \beta$-HSD1 promoter was significantly inhibited by PVE. In addition, PVE inhibited $11 \beta$-HSD1 mRNA levels induced by cortisone, in a concentration-dependent manner (Figure 1(b)). Cytotoxicity was not observed when the cells were incubated with $10 \sim 200$ ppm of PVE $24 \mathrm{~h}$ (Figure 2(c)).

3.3. PVE Inhibits Cortisol Production in HaCaT Cells. Keratinocytes are known to interconvert hormonally inert cortisone into active cortisol through the activation of the enzyme, $11 \beta$-HSD1 [6]. Thus, we investigated the effect of PVE on the production of cortisol in cortisone-induced $\mathrm{HaCaT}$ cells. The presence of PVE at a final concentration of 200 ppm significantly inhibited cortisol production (Figure 3). Comparable results were obtained with PVE, BVT2766 (a selective 11 $\beta$ HSD1 inhibitor) on inhibition assay for cortisol production (Figure 3). These results suggest that the PVE-mediated inhibition of cortisol is associated with the inhibition of $11 \beta$ HSD1 activity. 


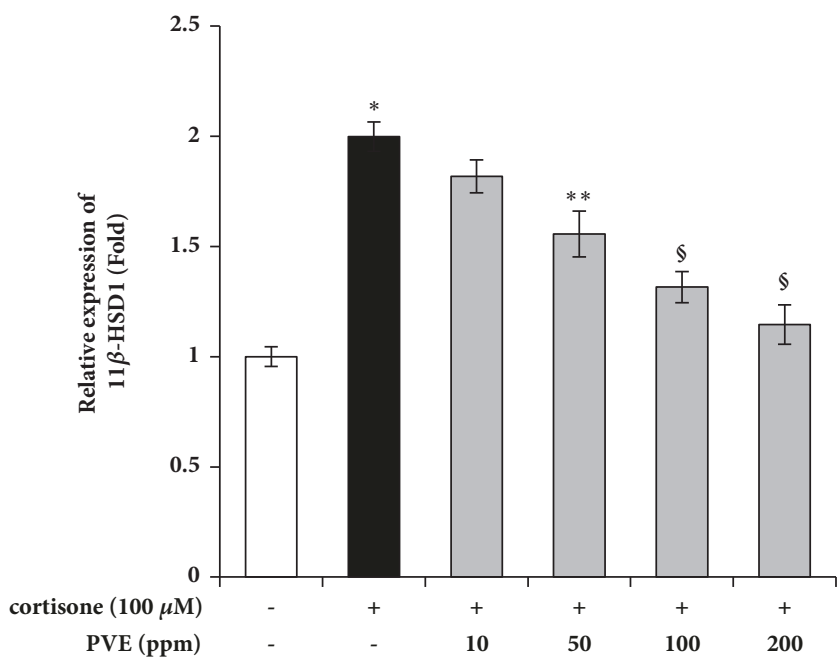

(a)

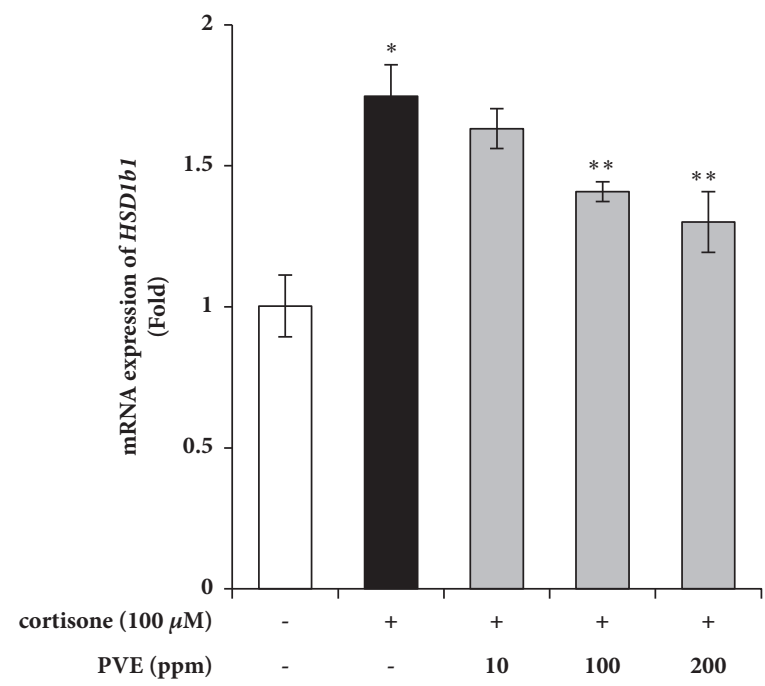

(b)

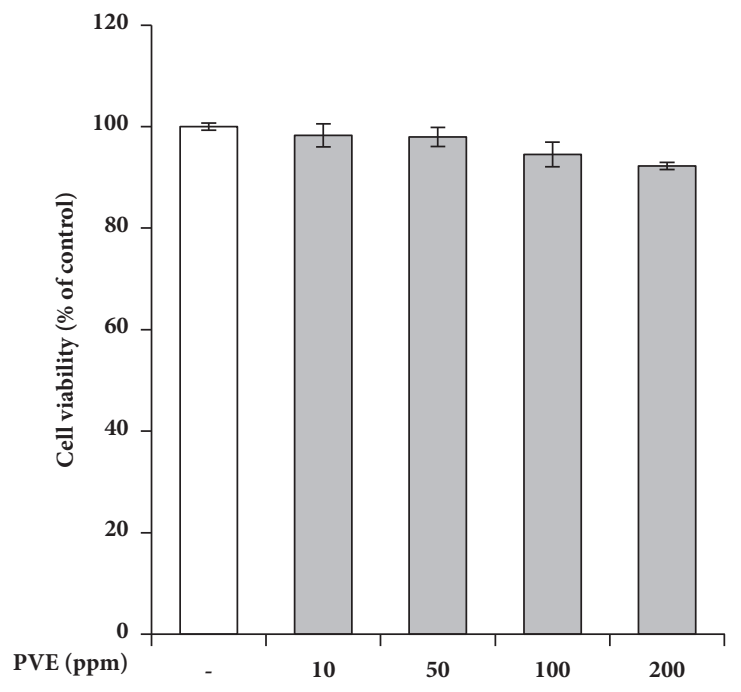

(c)

FIGURE 2: Effects of PVE on 11 $\beta$-HSD1 expression in cortisone-induced HaCaT cells. (a) The $11 \beta$-HSD1 promoter-luciferase reporter vector was transfected into HaCaT cells and cultured for $24 \mathrm{~h}$. The cells were pretreated with PVE for $1 \mathrm{~h}$ and then treated with cortisone. Luciferase activity was assessed against cortisone-treated control. (b) Cells were cultured in serum-free DMEM, in the presence of indicated concentrations of PVE, for $24 \mathrm{~h}$. The level of 11 $\beta$-HSD mRNA was assayed by quantitative real-time PCR. (c) Cell viability was performed by MTT assay. The results are mean \pm standard deviation (SD) ( $\mathrm{n}=3) . * P<0.01$ versus cortisone-untreated control. $* * P<0.05$ versus cortisonetreated control. $\$ P<0.01$ versus cortisone-treated control.

3.4. PVE Inhibits Cortisone-Induced GR Translocation. The biological action of glucocorticoids is mediated by the glucocorticoid recep tor (GR), a member of the nuclear receptor superfamily of ligand-dependent transcription factors that are encoded by a single gene in human and mice called NR3C1 [25]. Once inside the nucleus, GR binds directly to glucocorticoid response element (GRE) and stimulates the transactivation of aging-related genes. We investigated whether PVE would regulate the expression and translocation of GR. The expression of the GR gene, NR3C1, was upregulated by cortisone, and its gene level was downregulated by PVE (Figure 4(a)). Subsequently, we performed immunocytochemistry for GR, to analyze GR translocation from cytosol to nuclei. The immunocytochemical studies revealed that externally added cortisone induces translocation of GR into the nucleus (Figure 4(b)). Simultaneous incubation with PVE blocked GR translocation, indicating inhibition of $11 \beta$-HSD1-dependent conversion of cortisone to cortisol (Figure 4(b)). These results suggest that GC-induced GR expression and nuclear translocation were inhibited by PVE (Figure 4).

3.5. PVE Prevents the Cortisone-Induced Collagen Decrease. Cortisol is known to reduce the cellular amounts of type I 


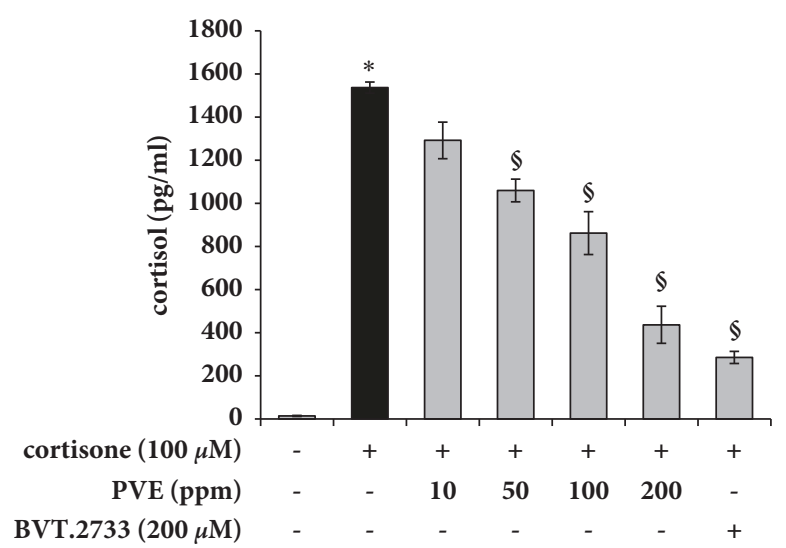

FIGURE 3: Effects of PVE on cortisol production in cortisone-induced HaCaT cells. The HaCaT cells were pretreated with PVE for $1 \mathrm{~h}$ before treatment with cortisone $(100 \mu \mathrm{M})$. The concentration of cortisol in the culture medium was measured by ELISA. The results are mean \pm standard deviation (SD) $(\mathrm{n}=3) . * P<0.01$ versus cortisone-untreated control. $\$ P<0.01$ versus cortisone-treated control.

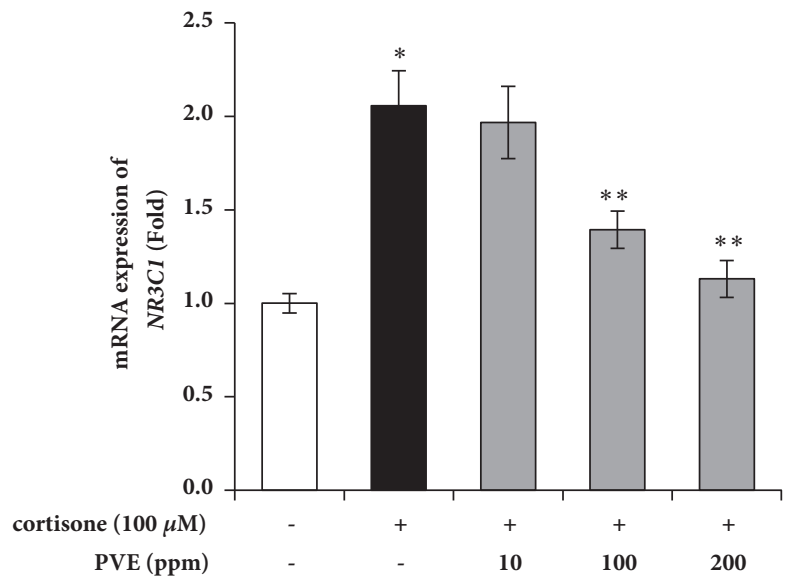

(a)
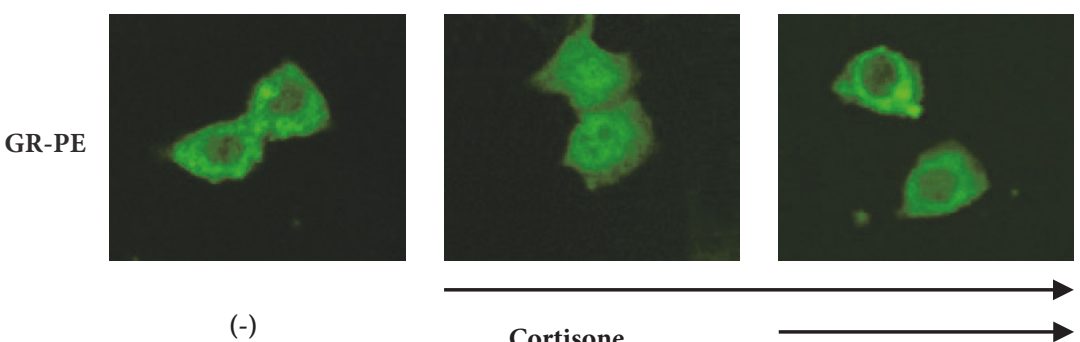

$(-)$

Cortisone

$100 \mu \mathrm{M}$
PVE 100 ppm

(b)

FIGURE 4: Effects of PVE on activation of GR in cortisone-treated HaCaT cells. (a) The HaCaT cells were cultured in serum-free DMEM, in the presence of an indicated concentration of PVE, for $24 \mathrm{~h}$. NR3C1 mRNA levels were assayed by quantitative real-time PCR. (b) The HaCaT cells were treated with PVE for $1 \mathrm{~h}$, before treatment with cortisone $(100 \mu \mathrm{M})$. After $40 \mathrm{~min}$ of stimulation, the cells were fixed, permeabilized, and incubated with PE-conjugated antihuman GR. GR-PE was analyzed using the IN Cell Analyzer 1000 instrument. The results are mean \pm standard deviation (SD) $(\mathrm{n}=3) . * P<0.001$ versus cortisone-untreated control. $* * P<0.05$ versus cortisone-treated control.

procollagen [26]. To investigate the effect of PVE on cortisolinduced inhibition of collagen synthesis, human epidermal keratinocytes (HEKn) were cocultured with human dermal fibroblasts (NHFs) using a transwell culture system.
HEKn in the upper chamber were pretreated with PVE or BVT.2733, a selective $11 \beta$-HSD1 inhibitor, and then stimulated with cortisone. Collagen levels were significantly decreased upon exposure to $100 \mu \mathrm{M}$ of cortisone. The treatment with 


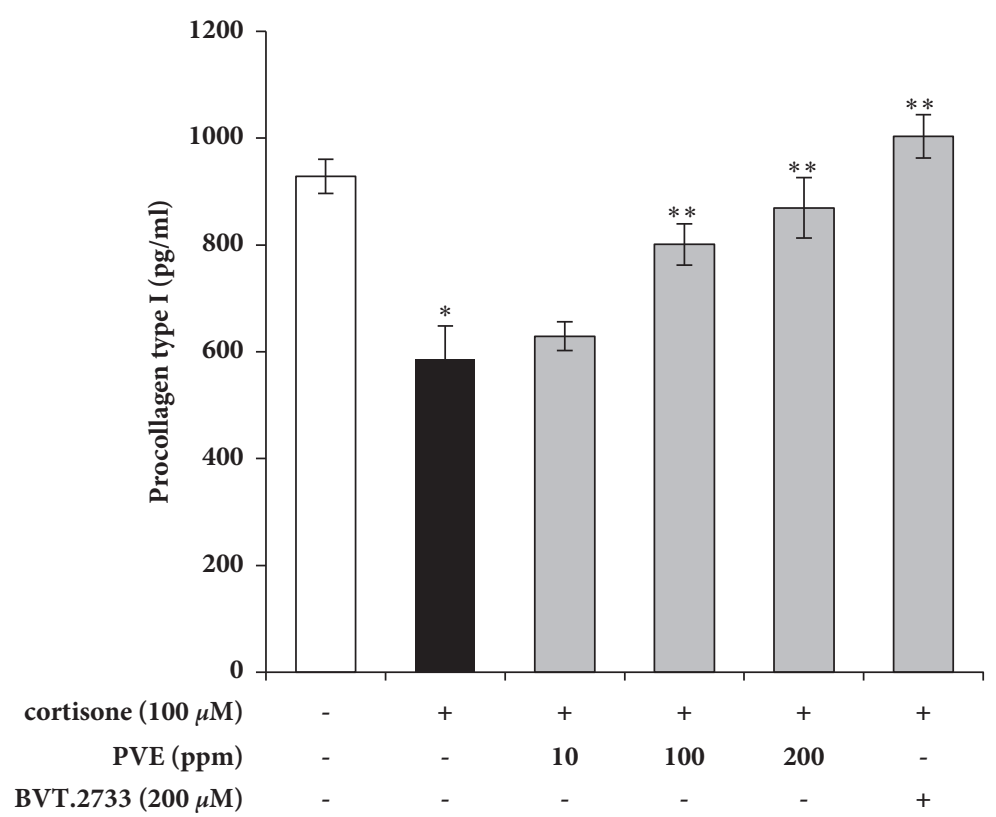

(a)

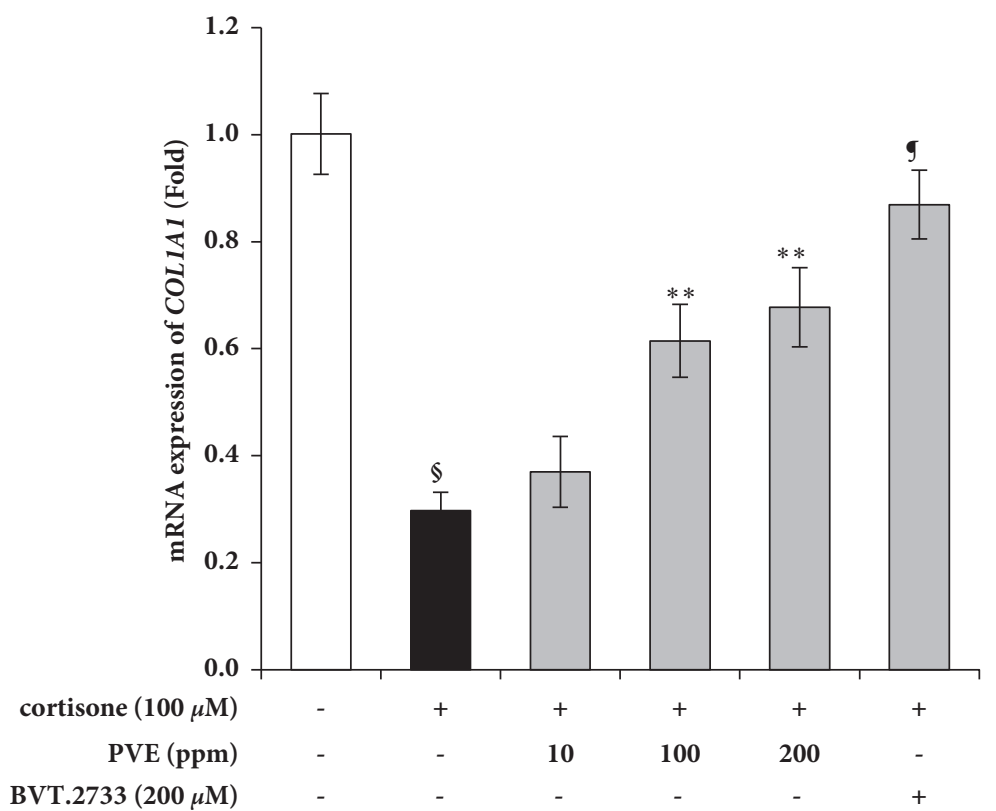

(b)

FIGURE 5: Effects of PVE on cortisol levels stimulated with cortisone in HEKn/NHFs coculture. The HEKn were seeded in upper chambers and NHFs were seeded in lower chambers of two-compartment transwell system for $24 \mathrm{~h}$. Upper chambers were pretreated with PVE and 11 $\beta$-HSD1 inhibitor, BVT.2733, and subsequently with cortisone. The HEKn were placed in the upper chamber with $8 \mu \mathrm{m}$-pore filters. (a) Procollagen type I was measured using ELISA. (b) COL1A1 mRNA levels were assayed by quantitative real-time PCR. The results are mean \pm standard deviation (SD) $(\mathrm{n}=3) . * P<0.05$ versus cortisone-untreated control, $* * P<0.05$ versus cortisone-treated control, $\$ P<0.01$ versus cortisone-untreated control, $\mathbf{g} P<0.01$ versus cortisone-treated control.

cortisone and either PVE or $11 \beta$-HSD1 inhibitor prevented the cortisone-induced collagen decrease at both mRNA and protein levels (Figures 5(a) and 5(b)). These results indicate that PVE-mediated inhibition of $11 \beta$-HSD 1 can prevent the decrease in collagen levels upon exposure to cortisone.

\section{Discussion}

Systemic GCs produced by HPA axis have been studied in the laboratory and in clinical trials. Cortisol is one of the major endogenous GCs, which is released in response to a various physical stressor and psychological stress. Recent 
studies have focused on local cortisol production by their activating enzyme. The enzyme, $11 \beta-\mathrm{HSD} 1$ is known to catalyze the conversion of inert cortisone to active cortisol in skin cells. Skin is a target of key stress mediators and is a local source of inducing various immune and inflammation responses. However, augment innate and adaptive immune responses and chronic stress can have deleterious effects on the skin. Long-term topical GCs treatment leads to severe skin atrophy, including decreased epidermal thickness, flat dermal-epidermal junction, and disruption of the dermal fibrous network. Therefore, regulation of $11 \beta$-HSD1 is a target for maintaining skin homeostasis.

GCs have effects on dermis and epidermis that is connected to the basement membrane. Keratinocytes are the major constituents of epidermis attached to the basement membrane. The dermis is mainly composed of fibroblasts which are responsible for making the extracellular matrix and collagen as the main component of connective tissue. The basement membrane is composed of two layers, the basal lamina and the underlying layer of reticular connective tissue, which ensures the stability of connection and communication between these two compartments. Thus, the expression of $11 \beta$-HSD1 within the epidermis and the dermis represents specific mechanism in the regulation of GC activation.

In this study, we found that a selective inhibitor (in PVE) of $11 \beta$-HSD1 had a strong inhibitory activity on cortisol activation in keratinocytes. After diffusion into the cells, GCs bind to the intracellular GC receptor (GR), induce a structural change in the GR molecule, and translocate the activated GR to the nucleus. The translocated GC/GR complex binds to GRE and affects gene expression either positively or negatively. Therefore, antagonism of the GR has been used to minimize the detrimental effects caused by chronically elevated GC levels.

Water extract of PV is mainly composed of rosmarinic acid and caffeic acid (Figure 1). Rosmarinic acid, a major constituent, showed independent inhibitory activity of $11 \beta$ HSD1, whereas caffeic acid was not observed (supplementary Figure 1). Further active component identification and bioavailability studies will help reveal more about PV as a mediator of GC-associated skin disease.

The degradation of ECM proteins in fibroblasts results in loss of the fundamental mechanical properties of the skin structure. Type I collagen, a heterodimer composed of three $\alpha$-chains encoded by COL1A1 and COL1A2 genes, is a major component of ECM [27]. Smad is essential for induction of type I collagen transcription and GR has a negative effect on Smad-activated gene transcription [28, 29]. GCs also decrease procollagen gene expression through GRE [30]. We have shown that PVE treatment of HEKn decreases $11 \beta$-HSD1 mRNA and cortisol levels stimulated by cortisone. These results concomitantly enhance collagen synthesis by regulating the GC mediated collagen degradation. Furthermore, studies on the regulation of various ECM proteins affected by GC may provide a more advanced approach to skin therapy. Therefore, $11 \beta$-HSD1 inhibitors may have beneficial applications in minimizing side effects associated with topical GC therapy such as skin atrophy [7].

\section{Conclusions}

We investigated the inhibitory effect of PVE on cortisol formation and found the inhibition of $11 \beta$-HSD1 as an underlying mechanism. Consistent with these results, cortisoneinduced translocation of glucocorticoids receptor (GR) was also attenuated. These inhibitory effects of PVE showed potential in the regulation of collagen gene expression. Based on our results, it is proposed that PVE may be used for maintaining skin integrity by inhibiting $11 \beta$-HSD11 activity.

\section{Data Availability}

The data that support the findings of this study are available from the corresponding author upon reasonable request.

\section{Conflicts of Interest}

The authors declare that there are no conflicts of interest regarding the publication of this paper.

\section{Acknowledgments}

This study was supported by a grant from the Ministry of Trade, Industry and Energy, Republic of Korea (R0005805).

\section{Supplementary Materials}

Supplementary Figure 1: effects of caffeic acid, rosmarinic acid, and PVE on cortisol production in cortisone-induced HaCaT cells. (Supplementary Materials)

\section{References}

[1] R. M. Sapolsky, L. M. Romero, and A. U. Munck, "How do glucocorticoids influence stress responses? Integrating permissive, suppressive, stimulatory, and preparative actions," Endocrine Reviews, vol. 21, no. 1, pp. 55-89, 2000.

[2] J. R. Revollo and J. A. Cidlowski, "Mechanisms generating diversity in glucocorticoid receptor signaling," Annals of the New York Academy of Sciences, vol. 1179, pp. 167-178, 2009.

[3] V. Viau, "Functional cross-talk between the hypothalamicpituitary-gonadal and -Adrenal axes," Journal of Neuroendocrinology, vol. 14, no. 6, pp. 506-513, 2002.

[4] E. M. Sternberg, "Neuroendocrine regulation of autoimmune/inflammatory disease," Journal of Endocrinology, vol. 169, no. 3, pp. 429-435, 2001.

[5] B. R. Walker and R. Andrew, "Tissue production of cortisol by $11 \beta$-hydroxysteroid dehydrogenase type 1 and metabolic disease," Annals of the New York Academy of Sciences, vol. 1083, pp. 165-184, 2006.

[6] N. Cirillo and S. S. Prime, "Keratinocytes synthesize and activate cortisol," Journal of Cellular Biochemistry, vol. 112, no. 6, pp. 1499-1505, 2011.

[7] A. Tiganescu, E. A. Walker, R. S. Hardy, A. E. Mayes, and P. M. Stewart, "Localization, age- and site-dependent expression, and regulation of $11 \beta$-hydroxysteroid dehydrogenase type 1 in skin," Journal of Investigative Dermatology, vol. 131, no. 1, pp. 30-36, 2011. 
[8] T. Kimura and K. Doi, "Dorsal Skin Reactions of Hairless Dogs to Topical Treatment with Corticosteroids," Toxicologic Pathology, vol. 27, no. 5, pp. 528-535, 1999.

[9] S. Schoepe, H. Schäcke, E. May, and K. Asadullah, "Glucocorticoid therapy-induced skin atrophy," Experimental Dermatology, vol. 15, no. 6, pp. 406-420, 2006.

[10] A. Tiganescu, A. A. Tahrani, S. A. Morgan et al., " $11 \beta-$ Hydroxysteroid dehydrogenase blockade prevents age-induced skin structure and function defects," The Journal of Clinical Investigation, vol. 123, no. 7, pp. 3051-3060, 2013.

[11] L. Kolbe, A. M. Kligman, V. Schreiner, and T. Stoudemayer, "Corticosteroid-induced atrophy and barrier impairment measured by non-invasive methods in human skin," Skin Research and Technology, vol. 7, no. 2, pp. 73-77, 2001.

[12] J. R. Seckl and B. R. Walker, "Minireview: $11 \beta$-hydroxysteroid dehydrogenase type 1-a tissue-specific amplifier of glucocorticoid action," Endocrinology, vol. 142, no. 4, pp. 1371-1376, 2001.

[13] M. Terao, H. Murota, A. Kimura et al., "11 $\beta$-hydroxysteroid dehydrogenase-1 is a novel regulator of skin homeostasis and a candidate target for promoting tissue repair," PLoS ONE, vol. 6, no. 9, 2011.

[14] J. Psotová, M. Kolář, J. Soušek, Z. Švagera, J. Vičar, and J. Ulrichová, "Biological Activities of Prunella vulgaris Extract," Phytotherapy Research, vol. 17, no. 9, pp. 1082-1087, 2003.

[15] X. Fang, R. C.-C. Chang, W.-H. Yuen, and S. Y. Zee, "Immune modulatory effects of Prunella vulgaris L.," International Journal of Molecular Medicine, vol. 15, no. 3, pp. 491-496, 2005.

[16] S. Kageyama, M. Kurokawa, and K. Shiraki, "Extract of Prunella vulgaris spikes inhibits HIV replication at reverse transcription in vitro and can be absorbed from intestine in vivo," Antiviral Chemistry \& Chemotherapy, vol. 11, no. 2, pp. 157-164, 2000.

[17] H.-X. Xu, S. H. S. Lee, S. F. Lee, R. L. White, and J. Blay, "Isolation and characterization of an anti-HSV polysaccharide from Prunella vulgaris," Antiviral Research, vol. 44, no. 1, pp. 4354, 1999.

[18] M. Hammwöhner, A. Ittenson, J. Dierkes et al., "Platelet expression of CD40/CD40 ligand and its relation to inflammatory markers and adhesion molecules in patients with atrial fibrillation," Experimental Biology and Medicine, vol. 232, no. 4, pp. 581-589, 2007.

[19] S. H. Park, H. J. Koo, Y. Y. Sung, and H. K. Kim, "The protective effect of Prunella vulgaris ethanol extract against vascular inflammation in TNF- $\alpha$-stimulated human aortic smooth muscle cells," BMB Reports, vol. 46, no. 7, pp. 352-357, 2013.

[20] Y.-J. Hwang, E.-J. Lee, H.-R. Kim, and K.-A. Hwang, "In vitro antioxidant and anticancer effects of solvent fractions from prunella vulgaris var. lilacina," BMC Complementary and Alternative Medicine, vol. 13, article 310, 2013.

[21] J. Zheng, J. He, B. Ji, Y. Li, and X. Zhang, "Antihyperglycemic activity of Prunella vulgaris L. in streptozotocin- induced diabetic mice," Asia Pacific Journal of Clinical Nutrition, vol. 16, no. 1, pp. 427-431, 2007.

[22] S. M. Hwang, J. S. Kim, Y. J. Lee et al., "Anti-diabetic atherosclerosis effect of Prunella vulgaris in $\mathrm{db} / \mathrm{db}$ mice with type 2 diabetes," American Journal of Chinese Medicine, vol. 40, no. 5, pp. 937-951, 2012.

[23] K. Roh, H. Kim, S. Shin et al., "Anti-inflammatory effects of Zea mays L. husk extracts," BMC Complementary and Alternative Medicine, vol. 16, no. 1, 2016.

[24] T.-F. Tzeng, W. Y. Liu, S.-S. Liou, T.-Y. Hong, and I.-M. Liu, "Antioxidant-rich extract from plantaginis semen ameliorates diabetic retinal injury in a streptozotocin-induced diabetic rat model," Nutrients, vol. 8, no. 9, 2016.

[25] R. H. Oakley and J. A. Cidlowski, "The biology of the glucocorticoid receptor: new signaling mechanisms in health and disease," The Journal of Allergy and Clinical Immunology, vol. 132, no. 5, pp. 1033-1044, 2013.

[26] L. Hamalainen, J. Oikarinen, and K. I. Kivirikko, "Synthesis and degradation of type I procollagen mRNAs in cultured human skin fibroblasts and the effect of cortisol," The Journal of Biological Chemistry, vol. 260, no. 2, pp. 720-725, 1985.

[27] E. Vuorio and B. De Crombrugghe, "The family of collagen genes," Annual Review of Biochemistry, vol. 59, pp. 837-872, 1990.

[28] S.-J. Chen, W. Yuan, S. Lo, M. Trojanowska, and J. Varga, "Interaction of smad3 with a proximal smad-binding element of the human $\alpha 2$ (I) procollagen gene promoter required for transcriptional activation by TGF- $\beta$," Journal of Cellular Physiology, vol. 183, no. 3, pp. 381-392, 2000.

[29] C.-Z. Song, X. Tian, and T. D. Gelehrter, "Glucocorticoid receptor inhibits transforming growth factor- $\beta$ signaling by directly targeting the transcriptional activation function of Smad3," Proceedings of the National Acadamy of Sciences of the United States of America, vol. 96, no. 21, pp. 11776-11781, 1999.

[30] N. Meisler, S. Shull, R. Xie et al., "Glucocorticoids coordinately regulate type I collagen pro $\alpha 1$ promoter activity through both the glucocorticoid and transforming growth factor $\beta$ response elements: A novel mechanism of glucocorticoid regulation of eukaryotic genes," Journal of Cellular Biochemistry, vol. 59, no. 3, pp. 376-388, 1995. 


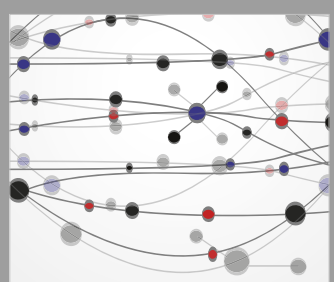

The Scientific World Journal
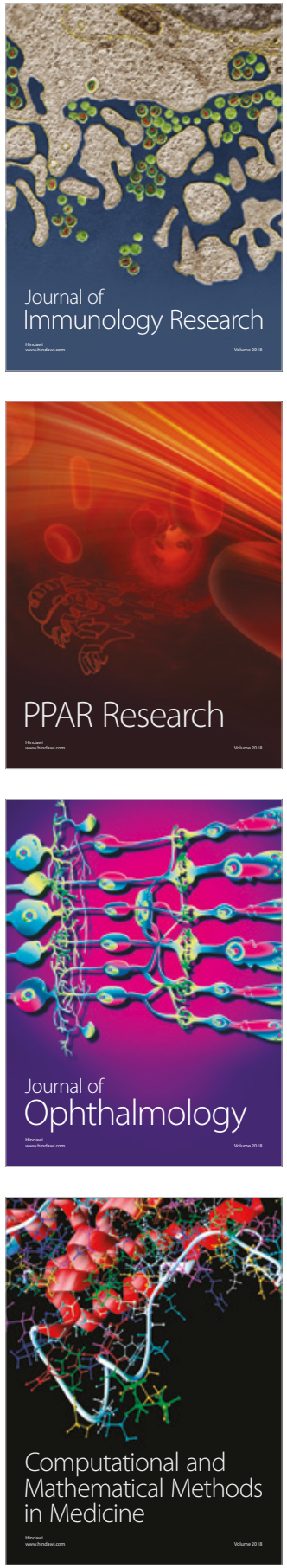

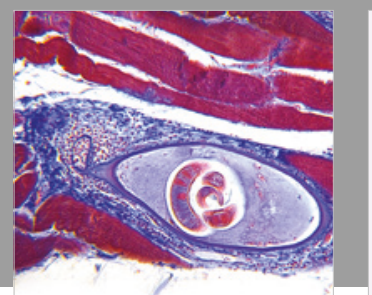

Gastroenterology Research and Practice

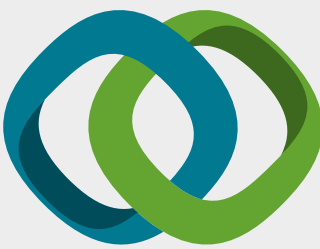

\section{Hindawi}

Submit your manuscripts at

www.hindawi.com
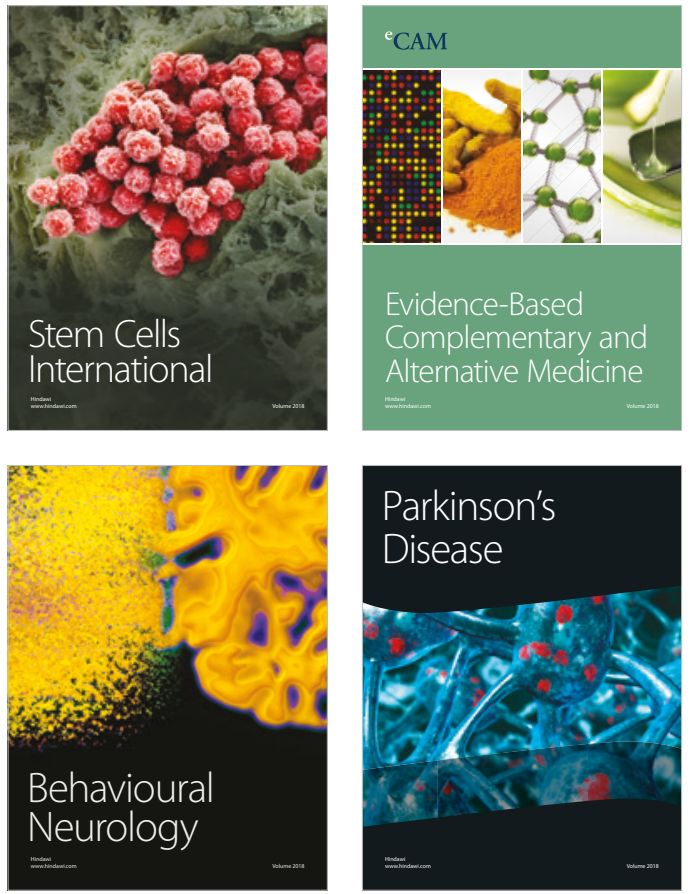

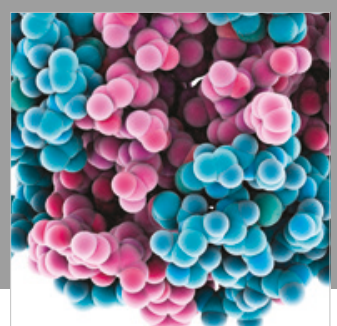

ournal of

Diabetes Research

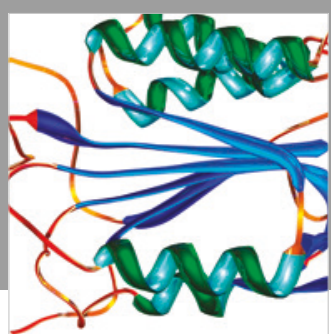

Disease Markers
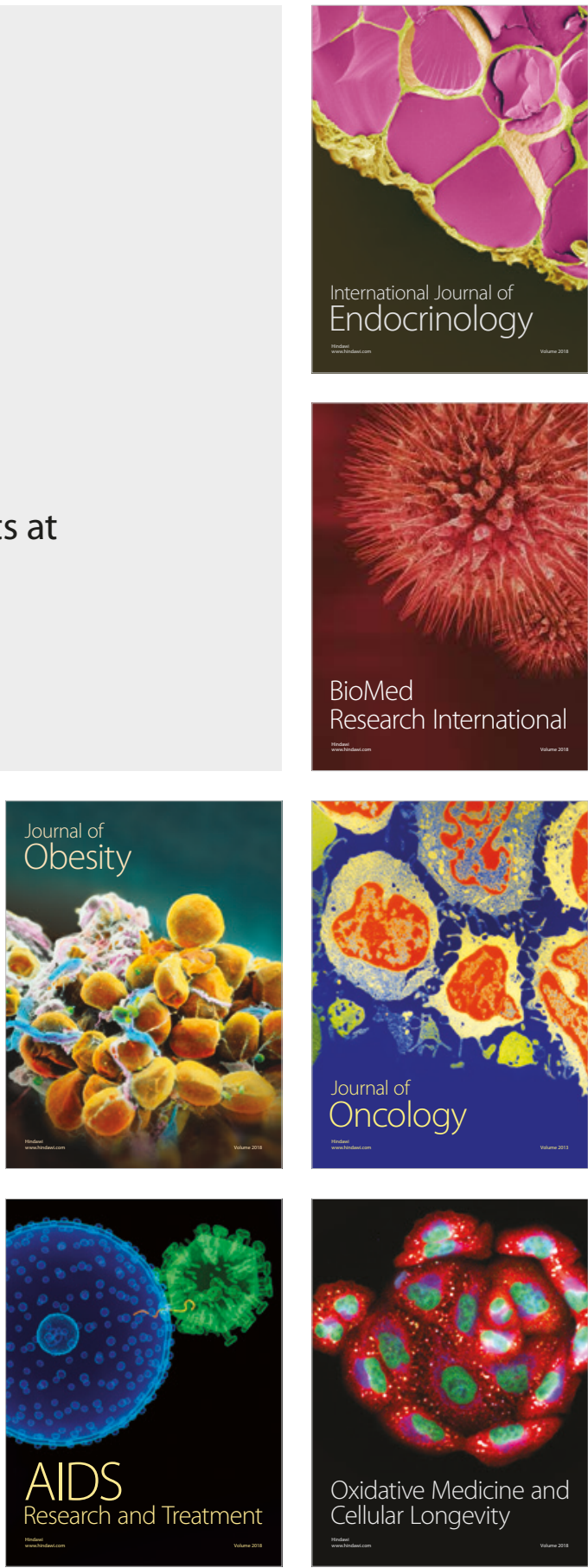